\title{
Evaluation of Triple Neurotization Technique as a Single Procedure in Adult Traumatic Brachial Plexus Injury
}

\author{
Shady Hermena ${ }^{1}$, Tarek El-Gammal ${ }^{2}$, Amr El-Sayed ${ }^{2}$, Mohamed M. Kotb ${ }^{2}$ \\ 1. Trauma and Orthopedics, Yeovil District Hospital, Yeovil, GBR 2. Trauma and Orthopedics, Assiut University \\ Hospital, Assiut, EGY
}

Corresponding author: Shady Hermena, shadypaulis@hotmail.com

\begin{abstract}
Introduction: Brachial plexus injuries are common and result in significant disabilities. This study evaluated the outcome of triple neurotization as a single procedure for upper trunk brachial plexus injury.

Patients and Methods: Some 25 adult consecutive patients with injured upper trunk brachial plexus who underwent microscopic reconstructive surgery using triple neurotization technique in the authors' institute were recruited in this study. Data on operative and functional outcomes were captured. Modified Narkas scale was used to evaluate the shoulder function in addition to Waikakul scale which was used to evaluate the elbow function. Data were analyzed with respect to short and long term with a median follow-up duration of two years.
\end{abstract}

Results: Assessment of the recovered shoulder abduction was excellent in $48 \%(\mathrm{n}=12)$, good in $24 \%$ ( $\mathrm{n}=6$ ), fair in $16 \%(n=4)$, and poor in $12 \%$ of cases $(n=3)$. Shoulder external rotation recovery was excellent in $48 \%$ $(n=12)$, good in $12 \%(n=3)$, fair in $12 \%(n=3)$, and poor in $28 \%$ of cases $(n=7)$. Recovery of elbow flexion was excellent in $60 \%(n=15)$, good in $12 \%(n=3)$, fair in $12 \%(n=3)$, and poor in $16 \%$ of cases $(n=4)$. The mean value of recovered shoulder abduction was 111.26 degrees (range: 70-150). The mean value of restored shoulder external rotation was 57.5 degrees (range: 45-70). The mean value of restored elbow flexion was 75 degrees (range: 55-120).

Conclusion: Triple neurotization technique can be effective to restore elbow flexion, shoulder abduction, and external rotation in adult patients with upper trunk brachial plexus injury.

Received 01/08/2020 Review began 01/10/2020 Review ended 01/11/2020 Published 01/15/2020

(c) Copyright 2020 Hermena et al. This is an open access article distributed under the terms of the Creative Commons Attribution License CC-BY 3.0., which permits unrestricted use, distribution, and reproduction in any medium, provided the original author and source are credited.
Categories: Orthopedics, Trauma

Keywords: brachial plexus injury, triple neurotization

\section{Introduction}

Adult traumatic brachial plexus injuries are common injuries resulting in significant disabilities [1]. Most of these injuries are caused by closed traction or compression forces, causing nerves avulsion, rupture, or stretching [2]. However, it can also be caused by open mechanisms, either iatrogenic injury during mastectomy or rib resection surgeries or stab injuries. The optimal timing for reconstructive brachial plexus procedures is within six months [3]. Surgery delayed for more than 18-24 months usually results in poor outcomes due to muscle fibers fatty degeneration [4]. Conservative treatment outcomes are usually unsatisfactory [5-10]. Triple neurotization means nerve transfer of spinal accessory nerve to suprascapular nerve, ulnar fascicles to biceps branch of musculocutaneous nerve, and triceps long or lateral head branch to axillary nerve to restore elbow flexion, shoulder abduction, and external rotation. There is little evidence on this technique in adult traumatic brachial plexus injuries. The purpose of this study was to evaluate the results of triple neurotization as a single procedure to restore shoulder abduction, external rotation, and elbow flexion after upper trunk brachial plexus injury.

\section{Materials And Methods}

After ethical approval by our institution's Human Studies Committee, a retrospective chart review was performed. Adult post-traumatic brachial plexus palsy patients were included in this study with no secondary reconstruction around the shoulder before or after the nerve transfer. Patients were followed up for at least 18 months.

\section{Operative technique}

The standardized operative protocol was followed, which involved positioning patients supine with prepared and draped both legs in case sural nerve graft was needed. During the first stage, an incision was made along the posterior edge of the sternocleidomastoid muscle and parallel to the lower border of the clavicle to expose the supraclavicular part of brachial plexus. Then a $10-\mathrm{cm}$ incision was made on the anteromedial 


\section{Cureus}

aspect of the arm, and the musculocutaneous nerve was followed to find the biceps motor branch which was dissected free and divided for about $2 \mathrm{~cm}$ from entry to the muscle. The ulnar nerve was also identified through the same incision and dissected using microscopic magnification to isolate a motor fascicle. The chosen fascicle was separated and turned laterally and superiorly towards the motor branch of biceps and coated with 10-0 Ethilon without tension.

During the second stage, the upper limb was moved over the patient's chest and a posterior incision $10 \mathrm{~cm}$ long was made beginning at the scapula lateral border. The axillary nerve was dissected and sectioned proximal to the teres minor branch. Then the triceps lateral head motor branch of radial nerve was dissected, sectioned, and flipped $180^{\circ}$ to be coapted to the axillary nerve under the microscope using microsutures.

During the third stage, we changed patient position to lateral position, and a 12 - to 15 -cm long incision was made parallel to the spine of the scapula. Trapezius muscle was lifted up, and the spinal accessory nerve was isolated and taped. The upper border of the scapula was palpated for suprascapular notch and the suprascapular ligament was divided while protecting the underlying suprascapular nerve. The suprascapular nerve was mobilized proximally to allow sufficient length and coapted with distal spinal accessory nerve using 10-0 nylon suture. The standardized postoperative protocol was followed, including rehabilitation and regular physiotherapy when it was tolerated.

\section{Data collection and analysis}

Patients' demography, intraoperative findings, and immediate postoperative outcome data were collected. Modified Narakas scale (Table 1) [11] was used to evaluate the shoulder function in addition to Waikakul scale (Table 2) [12] to evaluate the elbow function at $6,12,18$, and 24 months for all tests. Data analysis produced median values; the range and mean of the functional scores where applicable. The data were recorded in an Excel spreadsheet and analyzed using SPSS statistical software (version 19; SPSS Inc, Chicago, IL, USA). Mann-Whitney U and Kruskal-Wallis tests of statistical hypotheses with $\mathrm{p}<0.05$ to indicate statistical significance were used throughout.

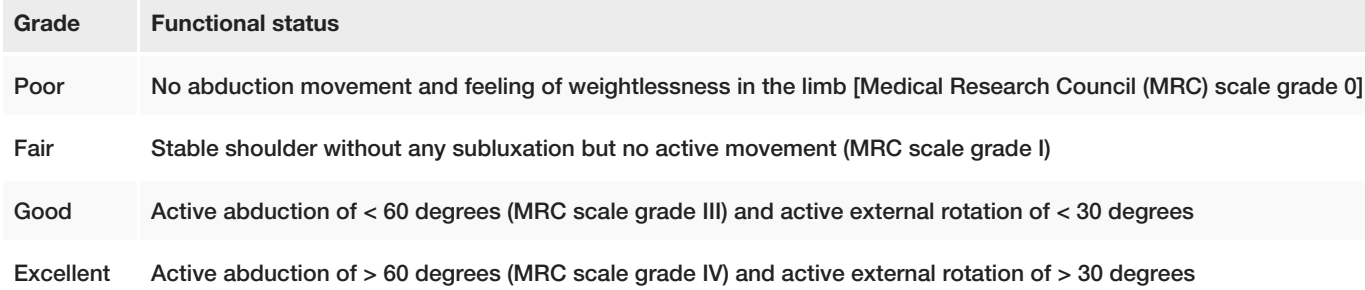

\section{TABLE 1: Modified Narakas scale for shoulder function grading.}

\begin{tabular}{|l|l|}
\hline \hline Grade & Functional status \\
\hline Excellent & Ability to lift $2 \mathrm{~kg}$ weight from 0 to 90 degrees of elbow flexion more than 30 times successively. \\
Good & Ability to lift $2 \mathrm{~kg}$ weight from 0 to 90 degrees of elbow flexion, but less than 30 repetitions successively. \\
Fair & Motor power more than MRC grade 3 power but unable to lift a 2 kg weight. \\
Poor & Motor power less than MRC grade 3. \\
\hline
\end{tabular}

TABLE 2: Waikakul scale for elbow function grading.

\section{Results}

Twenty-five patients (22 males and three females) with a median age at surgery of 29 years (20-50 years) were included in this study; all of them had triple neurotization and were followed up in our institute with a median follow up of two years. In the included patients, brachial plexus injury resulted from falling from a height, road traffic collision, and stab injuries. The right upper extremity was affected in $59 \%$ cases and left side in $41 \%$ cases. Intra-operative findings of the nerve roots status are summarized in Table 3. Minor postoperative complications included vomiting, and mild upper respiratory infection occurred in five cases (25\%), and they all were successfully treated. 


\section{Cureus}

\begin{tabular}{|c|c|c|c|c|c|}
\hline Intraoperative finding & C5 & C6 & C7 & C8 & T1 \\
\hline Intact root & 0 & 0 & 20 & 25 & 25 \\
\hline Avulsion & 18 & 20 & 3 & 0 & 0 \\
\hline Conducting neuroma & 2 & 0 & 0 & 0 & 0 \\
\hline Nonconducting neuroma & 5 & 5 & 2 & 0 & 0 \\
\hline Total & 25 & 25 & 25 & 25 & 25 \\
\hline
\end{tabular}

TABLE 3: Summary of intraoperative findings.

Restoration of shoulder abduction assessed by modified Narakas scale [11] was excellent in $48 \%$ ( $n=12)$, good in $24 \%(\mathrm{n}=6)$, fair in $16 \%(\mathrm{n}=4)$, and poor in $12 \%$ of cases $(\mathrm{n}=3)$. Shoulder external rotation recovery assessed by modified Narakas scale [11] was excellent in $48 \%(n=12)$, good in $12 \%(n=3)$, fair in $12 \%(n=3)$, and poor in $28 \%(n=7)$ of cases. Recovery of elbow flexion assessed using Waikakul scale [12] was excellent in $60 \%(n=15)$, good in $12 \%(n=3)$, fair in $12 \%(n=3)$, and poor in $16 \%$ of cases $(n=4)$. The mean postoperative value of shoulder abduction was 111.26 degrees (range: $70-150$ ) while preoperatively none of the patients were able for shoulder abduction $(\mathrm{p}<0.001)$. The mean postoperative value of shoulder external rotation was 57.5 degrees (range: $45-70$ ) while preoperative range of shoulder external rotation was zero $(\mathrm{p}<0.001)$. The mean postoperative value of elbow flexion was 75 degrees (range: 55-120) while preoperatively none of them were able for elbow flexion $(\mathrm{p}<0.001)$.

\section{Discussion}

Advanced reconstructive surgical options for brachial plexus injuries include nerve grafting, freefunctioning muscle transfers, and tendon transfers. Attempts of single nerve transfer have been successful in restoring the function of the affected joint. To restore the shoulder function, the spinal accessory nerve was transferred to the suprascapular nerve with good results for shoulder abduction and acceptable results for external rotation function [13-16]. Songcharoen et al. [17] reported $80 \%$ motor recovery grade 3 according to the Medical Research Council (MRC) scale [18] with $60^{\circ}$ of shoulder abduction and $45^{\circ}$ of shoulder flexion in the transfer of 577 spinal accessory nerves to the suprascapular nerve. To enhance the restored shoulder function, dual nerve transfer of the spinal accessory nerve to suprascapular nerve and the triceps branch of the radial nerve to axillary nerve have been introduced [19]. Literature reports that results of restored shoulder external rotation function are inferior to shoulder abduction function [20-26]. To recover elbow flexion, intercostal nerves or the spinal accessory nerves were transferred to the biceps motor branch of the musculocutaneous nerve [17, 26]. Oberlin [27] described transferring ulnar nerve motor fascicles to biceps motor branch with $85 \%$ good results of MRC grade 3 or better biceps strength.

In this study, we observed acceptable functional outcomes for both elbow flexion and shoulder abduction and rotation among 25 patients following this technique. There are two other studies which specifically addressed this topic that of Bertelli and Ghizoni [28] and Leechavengvongs et al. [29]. Bertelli and Ghizoni [28] reported full elbow flexion recovery, 92 degrees average shoulder abduction recovery, and 93 degrees average shoulder external rotation restoration after using triple neurotization technique to reconstruct C5 C6 brachial plexus avulsion injury in 10 patients. Leechavengvongs et al. [29] used triple neurotization technique to reconstruct 15 cases of $\mathrm{C} 5 \mathrm{C} 6$ brachial plexus injury and reported full elbow flexion recovery, 115 degrees average shoulder abduction recovery, and shoulder external rotation recovery averaging 97 degrees. Our results are generally comparable with those two studies; although the elbow flexion and shoulder external rotation were lower in our series, our shoulder abduction restoration average was higher.

We advocate a single procedure for triple surgery as not only it is very cost-effective, it also reduces exposure time to anesthesia and surgical stress with overall shorter hospital stay duration and rehabilitation time. This study, however, is not without its limitations. The sample size was relatively small, and not all of the data were collected prospectively; however, complete data collection was achieved in this cohort. This article only reports a single unit's practice and our results may not give a true reflection of outcomes that would be achieved in other units when using the same technique. We do, however, believe that our data support the safety and benefits of the application of triple neurotization as a single procedure for upper trunk brachial plexus injury, but more extensive studies from multiple centers are required.

\section{Conclusions}

Brachial plexus injuries result in significant disabilities. Nerve transfers, including different donor nerves, have been introduced to reinnervate the paralyzed muscles and to restore the elbow and shoulder function. In our study, we transferred spinal accessory nerve to suprascapular nerve, ulnar fascicles to biceps branch 
of musculocutaneous nerve, and triceps long or lateral head branch to axillary nerve. The results of this study showed that the triple neurotization technique could be effective to restore elbow flexion and shoulder abduction and external rotation in adult patients with upper trunk brachial plexus injury. However, the main limitations of this study are the small sample size and included results from a single unit. Further multicentred randomized controlled studies with bigger sample size are required to support this evidence.

\section{Additional Information \\ Disclosures}

Human subjects: Consent was obtained by all participants in this study. Assiut Faculty of Medicine Ethics Committe issued approval - This project was approved by the Assiut Faculty of Medicine Ethics Committee. Animal subjects: All authors have confirmed that this study did not involve animal subjects or tissue. Conflicts of interest: In compliance with the ICMJE uniform disclosure form, all authors declare the following: Payment/services info: All authors have declared that no financial support was received from any organization for the submitted work. Financial relationships: All authors have declared that they have no financial relationships at present or within the previous three years with any organizations that might have an interest in the submitted work. Other relationships: All authors have declared that there are no other relationships or activities that could appear to have influenced the submitted work.

\section{References}

1. Allieu Y, Cenac P: Is surgical intervention justifiable for total paralysis secondary to multiple avulsion injuries of the brachial plexus?. Hand Clin. 1988, 4:609-618.

2. Mackinnon SE, Dellon AL: Brachial plexus injuries. Surgery of the Peripheral Nerve. Mackinnon SE, Dellon AL (ed): Thieme, New York; 1988. 423-454.

3. Martin E, Senders JT, DiRisio AC, Smith TR, Broekman MLD : Timing of surgery in traumatic brachial plexus injury: a systematic review. J Neurosurg. 2019, 130:1333-1345.

4. Ferrante MA: Electrodiagnostic assessment of the brachial plexus. Neurol Clin. 2012, 30:551-580. 10.1016/j.ncl.2011.12.005

5. Tu YK, Chung KC: Surgical procedures for recovery of hand function . Practical management of pediatric and adult brachial plexus palsies. Chung KC, Yang LJS, McGillicuddy JE (ed): Saunders Elsevier, New York; 2012. 271-300.

6. Songcharoen P, Wongtrakul S, Mahaisavariya B, Spinner RJ: Hemicontralateral C7 transfer to the median nerve in the treatment of root avulsion brachial plexus injury. J Hand Surg Am. 2001, 26:1058-1064. 10.1053/ihsu.2001.27764

7. Thomeer RT, Malessy MJ: Surgical repair of brachial plexus injury. Clin Neurol Neurosurg. 1993, 95:65-72.

8. Narakas AO: The effects on pain of reconstructive neurosurgery in 160 patients with traction and/or crush injury to the brachial plexus. Phantom and Stump Pain. Siegfried J, Zimmermann M (ed): Springer, Berlin; 1981. 126-147.

9. Bentolila V, Nizard R, Bizot P, Sedel L: Complete traumatic brachial plexus palsy. Treatment and outcome after repair. J Bone Joint Surg Am. 1999, 81:20-28.

10. Doi K, Sakai K, Kuwata N, Ihara K, Kawai S: Double free-muscle transfer to restore prehension following complete brachial plexus avulsion. J Hand Surg Am. 1995, 20:408-414.

11. Azze RJ, Mattar Junior J, Ferreira MC, Starck R, Canedo AC: Extraplexal neurotization of brachial plexus . Microsurgery. 1994, 15:28-32.

12. Billet H: Les troncs primaires du plexus brachial. CR Assoc Anat Lisbonne. 1933, 32-63.

13. Bertelli JA, Ghizoni MF: Transfer of the accessory nerve to the Suprascapular nerve in brachial plexus reconstruction. J Hand Surg. 2007, 32:989-998.

14. Guan SB, Hou CL, Chen DS, Gu YD: Restoration of shoulder abduction by transfer of the spinal accessory nerve to suprascapular nerve through dorsal approach: a clinical study. Chin Med J. 2006, 119:707-712.

15. Suzuki K, Doi K, Hattori Y, Pagsaligan JM: Long-term results of spinal accessory nerve transfer to the suprascapular nerve in upper-type paralysis of brachial plexus injury. J Reconstr Microsurg. 2007, 23:295299. 10.1055/s-2007-985205

16. Terzis JK, Kostas I: Suprascapular nerve reconstruction in 118 cases of adult posttraumatic brachial plexus . Plast Reconstr Surg. 2006, 117:613-629. 10.1097/01.prs.0000203410.35395.fa

17. Songcharoen $P$, Wongtrakul S, Spinner RJ: Brachial plexus injuries in the adult. Nerve transfers: the Siriraj Hospital experience. Hand Clin. 2005, 21:83-89.

18. Medical Research Council: Aids to the examination of the peripheral nervous system . Memorandum no 45 . Her Majesty's Stationery Office, London; 1981.

19. Witoonchart K, Leechavengvongs S, Uerpairojkit C, Thuvasethakul P, Wongnopsuwan V: Nerve transfer to deltoid muscle using the nerve to the long head of the triceps, part I: an anatomic feasibility study. J Hand Surg. 2003, 28:628-632.

20. Terzis JK, Vekris MD, Soucacos PN: Outcomes of brachial plexus reconstruction in 204 patients with devastating paralysis. Plast Reconstr Surg. 1999, 104:1221-40. 10.1097/00006534-199910000-00001

21. El-Gammal TA, Fathi NA: Outcomes of surgical treatment of brachial plexus injuries using nerve grafting and nerve transfers. J Reconstr Microsurg. 2002, 18:7-15. 10.1055/s-2002-19703

22. Terzis JK, Kostas I, Soucacos PN: Restoration of shoulder function with nerve transfers in traumatic brachial plexus palsy patients. Microsurgery. 2006, 26:316-324.

23. Alnot JY, Rostoucher P, Oberlin C, Touam C: C5-C6 and C5-C6-C7 traumatic paralysis of the brachial plexus of the adult caused by supraclavicular lesions. Rev Chir Orthop Reparatrice Appar Mot. 1998, 84:113-123.

24. Vekris MD, Beris AE, Pafilas D, Lykissas MG, Xenakis TA, Soucacos PN: Shoulder reanimation in posttraumatic brachial plexus paralysis . Injury. 2010, 41:312-318. 10.1016/j.injury.2009.09.009 


\section{Cureus}

25. Songcharoen P: Brachial plexus injury in Thailand: a report of 520 cases . Microsurgery. 1995, 16:35-39.

26. Merrell GA, Barrie KA, Katz DL, Wolfe SW: Results of nerve transfer techniques for restoration of shoulder and elbow function in the context of a meta-analysis of the English literature. J Hand Surg. 2001, 26:303314.

27. Oberlin C, Béal D, Leechavengvongs S, Salon A, Dauge MC, Sarcy JJ: Nerve transfer to biceps muscle using a part of ulnar nerve for C5-C6 avulsion of the brachial plexus: anatomical study and report of four cases. J Hand Surg. 1994, 19:232-237.

28. Bertelli JA, Ghizoni MF: Reconstruction of C5 and C6 brachial plexus avulsion injury by multiple nerve transfers: spinal accessory to suprascapular, ulnar fascicles to biceps branch, and triceps long or lateral head branch to axillary nerve . J Hand Surg. 2004, 29:131-139.

29. Leechavengvongs S, Witoonchart K, Uerpairojkit C, Thuvasethakul P, Malungpaishrope K: Combined nerve transfers for C5 and C6 brachial plexus avulsion injury. J Hand Surg. 2006, 31:183-189. 